\title{
REFORMAS A LA LEGISLACIÓN AMBIENTAL ASOCIADO AL BIENESTAR ANIMAL EN MÉXICO.
}

Angel Daen Morales Garcia* y Jonatan Job Morales Garcia.

SUMARIO: 1. Introducción. 2. La legislación mexicana asociada al bienestar animal. 2.1. Bienestar animal y ecología. 3. Las Normas Oficiales Mexicanas asociadas al bienestar animal. 4. Reforma asociada al bienestar Animal en la Ley General del Equilibrio Ecológico y Protección al Ambiente. 5. Conclusiones.

\section{Introducción}

El bienestar animal inició como disciplina formal en Reino Unido con la publicación del reporte de Brambell sobre bienestar de animales en granjas en 1965, ${ }^{1}$ este informe es considerado como la investigación más influyente sobre bienestar de animales de gran- ja en condiciones intensivas de producción en el siglo $\mathrm{XX}^{2}$ debido a que estableció los cimientos para que los grupos de bienestar animal y derechos de los animales criticaran y trabajaran para mejorar las condiciones de los animales destinados a alimentación humana en los sistemas de producción animal, ${ }^{3}$ este reporte hacía referencia a que estos animales tuvieran suficiente espacio para moverse libremente, darse vuelta, acicalarse, levantarse, echarse y extender sus

\footnotetext{
*Abogado experto en Derecho Ambiental y Derecho Animal, Vicepresidente de Biofutura A.C., embajador de México COALITIONWILD, miembro de la Comisión Mundial de Derecho Ambiental (WCEL), Comisión Mundial de Áreas Protegidas (WCPA) y de la Comisión de Política Ambiental, Económica y Social (CPAES) de la Unión Internacional para la Conservación de la Naturaleza (IUCN), corresponsal en México de la web Derecho Animal.

${ }^{1}$ Brambell, F. Report of the Technical Committee to Enquire into the Welfare of Ani mals Kept under Intensive Livestock Husbandry Systems. Her Majesty's Stationery Of ce, London, UK. (1965).

2 David, C. Bienestar en peces y aspectos reglamentarios en Colombia para la explotación de especies ícticas con fines experimentales y comerciales. pp. 169-180. Revista Lasallista de Investigación. Vol. 11, (6). (2014).

${ }^{3}$ Guither Harold D. Animal rights. History and scope of a radical social movement. Pág. 2. Ed., Southern Illinois University Press. (1998).
} 
extremidades, lo que posteriormente dio pauta para la creación de las cinco libertades del Farm Animal Welfare Council (FAWC).

El bienestar animal es un estado que implica un conjunto de elementos físicos, psicológicos y ecológicos necesarios para que un animal no humano con capacidades sensitivas y cognitivas pueda desarrollarse en un entorno satisfactorio. El bienestar animal tiene una connotación antropogénica y debido a su naturaleza, es gradual, multidimensional $^{4}$ e individualizado por especie debido a las características diferenciadas que presenta la diversidad biológica de fauna. El Bienestar animal es un término interdisciplinario y multifacético que se interrelaciona con dimensiones científicas, éticas, económicas, políticas, ${ }^{5}$ sociales y ambientales, así mismo, se asocia con problemas socio ambientales como la crisis ambiental, por lo que este tópico se ha posicionado para desempeñar un papel importante en los grandes problemas que enfrenta la sociedad global en la actualidad. ${ }^{6}$

El bienestar animal asociado a los animales terrestres es conceptualizado por la Organización Mundial de Sanidad Animal en el Código Sanitario para los Animales Terrestres en el artículo 7.1.1. de la siguiente manera:

El término bienestar animal designa el modo en que un animal afronta las condiciones de su entorno. Un animal está en buenas condiciones de bienestar si (según indican pruebas científicas) está sano, cómodo, bien alimentado, en seguridad, puede expresar formas innatas de comportamiento y si no padece sensaciones desagradables de dolor, miedo o desasosiego. Las buenas condiciones de bienestar de los animales exigen que se prevengan sus enfermedades y se les administren tratamientos veterinarios apropiados; que se les proteja, maneje y alimente correctamente

\footnotetext{
${ }^{4}$ Manteca, X., Salas, M. Concepto de bienestar animal. https://www.zawec.org/media/com_lazypdf/pdf/Ficha\%20ZAWEC\%201.pdf (2015).

${ }^{5}$ Lund, V., Coleman, G., Gunnarsson, S., Appleby, M. C., \& Karkinen, K. Animal welfare science-Working at the interface between the natural and social sciences. pp. 37-49. Applied Animal Behaviour Science, 97 (1), (2006).

${ }^{6}$ Marchant-Forde, J. N. The science of animal behavior and welfare: challenges, opportunities, and global perspective. Frontiers in Veterinary Science, 2, (16), (2015).
} 


\section{dA derecho ANIMAL la web center de los animales con derecho}

y que se les manipule y sacrifique de manera compasiva. El concepto de bienestar animal se refiere al estado del animal. La forma de tratar a un animal se designa con otros términos como cuidado de los animales, cría de animales o trato compasivo.

Actualmente en los sistemas normativos el bienestar animal es un concepto dinámico que se origina como una oposición al sufrimiento de los demás animales por las actividades antropogénicas y se presenta como un elemento antagónico a la concepción clásica de considerar a los demás animales como cosas o bienes muebles, empero, aún prevalece esta visión errada e incluso en la generalidad es moralmente aceptable utilizar a los animales como recursos para las necesidades humanas incluyendo su sacrificio.

El bienestar animal tiene un vínculo intrínseco con el reconocimiento de los demás animales como seres sensibles, sin embargo, su origen en el sistema normativo mexicano se asociaba principalmente a temas de sanidad animal a fin de que no existieran perdidas económicas derivadas de la muerte de animales o un posible daño a la salud del humano. Pese al avance y posicionamiento de los derechos animales en la normatividad jurídica, la concepción jurídica actual del bienestar animal es limitativa al estar subordinado a los intereses humanos. ${ }^{7}$ El bienestar animal es un concepto que conforme el avance de la ciencia y la expansión del circulo moral hacia los demás seres con los que cohabitamos las actividades que implican maltrato y crueldad animal tienden a invisibilizarse y a prohibirse en los sistemas normativos principalmente las practicas que se asocian con especies con una importancia ecológica y social. Es precisamente el origen de la expansión del circulo de la compasión desde un enfoque social por el que la mayoría de legislaciones actuales de bienestar animal (en América y Europa) protegen principalmente a los perros y gatos, esto se da por que con estas especies el humano tiene una relación empática más sólida debido a los procesos de domesticación milenaria de estos

\footnotetext{
${ }^{7}$ Leyton, F. Bioética frente a los derechos animales: tensión en las fronteras de la filosofía moral. Pag. 248. Tesis doctoral dirigida por el Dr. Norbert Bilbeny y el Dr. Óscar Horta Álvarez. Barcelona: Universitat de Barcelona. Departament de Filosofia Teorètica i Pràctica. (2015).
} 
animales como mascotas. Desde una visión cultural asociada al bienestar animal existe un trato diferenciado hacia los animales en cada grupo social debido a la pluriculturalidad y a los vínculos que establece cada sociedad con la fauna, esto da resultado que algunas especies tengan una protección especial como las vacas en la República de India, las focas en la Unión Europea, pericos mexicanos, primates y mamíferos marinos en México o el panda en la República Popular de China.

\section{Legislación mexicana asociada al bienestar animal.}

El bienestar de los animales vinculado con el trato digno y respetuoso como una obligación jurídica en el sistema normativo mexicano se asociaba de manera indirecta con la sanidad animal y la economía, como antecedente legislativo del siglo $\mathrm{XX}$ es importante referir la Ley de Sanidad Fitopecuaria de los Estados Unidos Mexicanos, publicada en el Diario Oficial de la Federación (DOF) el 9 de septiembre de 1940, esta Ley establecía en el numeral 11 lo siguiente:

Articulo 11.- los propietarios y encargados de ganados están en la obligación de prodigarle los cuidados higiénicos zootécnicos que sean menester para conservarlos en las mejores condiciones de salud y defensa natural en contra de las enfermedades infecto-contagiosas. Queda prohibido a los mismos, hacer cruzamientos con sementales afectados de dichas enfermedades, transmisibles o posibles de transmitir por herencia.

La importancia de propiciar salud y cuidados higiénicos a los animales destinados a la ganadería era para reducir daños y riesgos a la salud humana. Esta Ley fue abrogada por la entrada en vigor de la Ley de Sanidad Fitopecuaria de los Estados Unidos Mexicanos, publicada en el DOF el 13 de Diciembre de 1974 que establecía como materia de sanidad fitopecuaria la protección y conservación sanitarias de los animales silvestres, especies pecuarias, aves para consumo o el de sus productos, abejas, conejos así como los animales de laboratorio, zoológico y los destinados a la producción peletera. Esta legislación consideraba como función de sanidad animal 
el realizar, promover y vigilar la aplicación de las medidas profilácticas, terapéuticas, higiénicas y, en general, de todas aquellas de carácter zootécnico que establezca la Secretaría de Agricultura y Ganadería. En esta legislación las medidas de seguridad en materia de sanidad animal tenían como objetivo proteger la salud de los animales y evitar la propagación de enfermedades o plagas que los afectaran. Estas legislaciones tenían los primeros indicios en materia de protección animal, empero, se asociaba a la salud humana y a la pérdida económica por daños a los animales por lo que el bienestar animal se presentó de manera indirecta.

El 18 de Junio de 1993 se publica en el DOF la Ley Federal de Sanidad Animal, que por primera vez vincula el bienestar animal al establecer el trato humanitario que conforme

$\mathrm{Al}$ artículo $2^{\circ}$, lo definía de la siguiente manera:

Articulo 2‥-(..)

Trato humanitario.- las medidas para evitar dolor innecesario a los animales durante su captura, traslado, exhibición, cuarentena, comercialización, aprovechamiento, entrenamiento y sacrificio;

Así mismo, se establece en el Titulo Segundo, de las medidas zoosanitarias, el Capítulo III denominado Del trato humanitario, cuidado zoosanitario y técnicas de sacrificio de animales, consagrando lo siguiente:

ARTICULO 17.- La Secretaría expedirá las normas oficiales que establezcan las características y especificaciones zoosanitarias para:

I.- El trato humanitario;

II.- El cuidado zoosanitario para que todo poseedor de animales los inmunice contra las enfermedades transmisibles de la especie prevalecientes en la zona, así como le proporcione la alimentación, higiene, movilización y albergue ventilado necesario, a fin de asegurar su salud; $y$ III.- Las técnicas de sacrificio de animales. 
Con estas disposiciones se establecía por primera vez en la legislación mexicana una obligación directa asociada al trato humanitario que se debe de tener con los animales. Después de 14 años, el 25 de Julio de 2007 se deroga esta legislación y se crea la Ley Federal de Sanidad Animal, legislación que sigue vigente en México, en relación con la procuración del bienestar animal se establece como uno de los objetos de la Ley enmarcados en el artículo 1, así mismo, la procuración del bienestar animal es una de las finalidades de la sanidad animal conforme al numeral 2, siendo la autoridad responsable de tutelar el bienestar animal la Secretaría de Agricultura, Ganadería, Desarrollo Rural, Pesca y Alimentación (SAGARPA) conforme al numeral 3. Esta legislación es un parteaguas ya que por primera vez se designa una definición al bienestar animal en el numeral 4, conforme a lo siguiente:

(...) Bienestar animal: Conjunto de actividades encaminadas a proporcionar comodidad, tranquilidad, protección y seguridad a los animales durante su crianza, mantenimiento, explotación, transporte y sacrificio.

Esta legislación establece en el capítulo I del título tercero lo referente al bienestar de los animales donde se establece la obligación de SAGARPA de establecer disposiciones de sanidad animal estableciendo las características y especificaciones para la procuración del bienestar animal que todo propietario o poseedor de animales deba proporcionar a los animales propiciando la inmunización contra enfermedades y plagas, alimentación, higiene, transporte, albergue y en su caso entrenamiento apropiado conforme a las características de cada especie animal, con el objetivo de evitar su estrés y asegurar su vida y salud, el articulo 20 consagraba por primera vez los principios de bienestar animal en cinco puntos:

I. Que exista una relación entre la salud de los animales y su bienestar. Que el bienestar de los animales requiere de proporcionarles alimentos y agua suficientes; evitarles temor, angustia, molestias, dolor $\mathrm{y}$ lesiones innecesarios; mantenerlos libres de enfermedades y plagas, y permitirles manifestar su comportamiento natural; 
II. La utilización de animales para actividades de investigación y educación, que les imponga procedimientos que afecten su salud y bienestar, observará el criterio de reducir al mínimo indispensable el número de animales vivos en experimentación, conforme a la evidencia científica disponible;

III. La evaluación del bienestar de los animales se sustentará en principios científicamente aceptados por los especialistas;

IV. El ser humano se beneficia de los animales de muy diversas maneras, y en ese proceso, adquiere la responsabilidad de velar por su bienestar; $y$

V. El estado de bienestar de los animales, utilizados por el ser humano con fines económicos, se asocia con mayor productividad y beneficios económicos.

El articulo 21 establece la obligación a los propietarios o poseedores de animales domésticos o silvestres en cautiverio de proporcionar alimento y agua en cantidad y calidad adecuada de acuerdo a su especie y etapa productiva los propietarios o poseedores de animales domésticos o silvestres en cautiverio. Así mismo, se establece que los animales en cautiverio deberán de estar sujetos a un programa de medicina preventiva bajo supervisión de un védico veterinario deberán ser revisados y atendidos regularmente, y en caso de enfermedad o lesión se les deberá de proporcionar atención inmediata.

El numeral 22 establece que la SAGARPA determinará los criterios y requisitos que deberán observarse en el transporte y manejo de animales vivos, procurando el bienestar animal por lo que estas actividades no deben producir maltrato, fatiga, inseguridad, condiciones no higiénicas, tener bebida y alimento necesario y evitar el traslado de largas distancias sin periodos de descanso.

El artículo 23 se asocia al sacrificio humanitario de cualquier animal no destinado al consumo humano, y establece que solamente estará justificado si el bienestar del animal está comprometido por el sufrimiento que le causen elementos externos como enfermedad, incapacidad física o trastornos seniles, de ser posible previo dictamen de un médico veterinario, se exceptúan las especies animales que por 
cualquier causa, la SAGARPA, las Secretarias de Salud o la Secretaria de Medio Ambiente y Recursos Naturales, determinen como una amenaza para la salud animal humana y no humana, o para el medio ambiente. Esta normatividad establece que sacrificio de los animales destinados al abasto se debe de realizar conforme a las técnicas de sacrificio que determine la SAGARPA a través de una norma oficial mexicana donde se establezcan las medidas, condiciones y procedimientos necesarios para la insensibilización y el sacrificio de animales.

\subsection{Bienestar animal y ecología.}

Los animales tienen una importancia diferenciada en el sistema normativo mexicano, desde una visión ecológica a nivel federal existen disposiciones que establecen temas asociados al bienestar animal principalmente en la Ley General del Equilibrio Ecológico y la Protección al Ambiente y la Ley General de Vida Silvestre. Ley General del Equilibrio Ecológico y la Protección al Ambiente establece en el numeral 79 que para la preservación y aprovechamiento sustentable de la flora y fauna silvestre, se considerará entre diversos criterios el fomento del trato digno y respetuoso a las especies animales, con el propósito de evitar la crueldad en contra de éstas.

En el numeral 87 Bis 2 se establecían los principios básicos del bienestar animal, este artículo fue adicionado mediante una reforma publicada en el Diario Oficial de la Federación el 13 de Diciembre de 1996, donde se establecía lo siguiente:

ARTÍCULO 87 BIS 2.- El Gobierno Federal, los gobiernos de los Estados, del Distrito Federal y de los Municipios, en el ámbito de sus respectivas competencias, regularán el trato digno y respetuoso que deberá darse a los animales.

Este numeral consagraba por primera vez las directrices del bienestar animal en sentido lato sin delimitar o excluir por especies, es decir, se da una protección a todos los animales. 
Posteriormente el 5 de Noviembre de 2013 se publicó en el DOF una reforma que adicionaba un segundo párrafo que establecía la competencia concurrente de los tres órdenes de gobierno para regular en su ámbito competencial el trato digno y respetuoso que deberá darse a los animales, estableciendo la obligación del gobierno federal para expedir normas oficiales mexicanas que determinen los principios básicos del trato digno y respetuoso previsto por esta Ley, que incluyan condiciones de cautiverio, exhibición, transporte, alimentación, explotación, manutención y sacrificio de los animales, así como vigilar su cumplimiento.

El 9 de Enero de 2015 se reformo el segundo párrafo del artículo 87 BIS 2 para simplemente agregar dentro de las actividades a regular las actividades realizadas con animales que se asociaban al entrenamiento y fue hasta la reforma del 24 de Enero de 2017 donde se concibe una visión más integral del bienestar animal.

La Ley General de Vida Silvestre, publicada el 3 de Julio del 2000 en el DOF, tiene como objeto en la actualidad establecer la concurrencia del Gobierno Federal, de los gobiernos de los Estados y de los Municipios, en el ámbito de sus respectivas competencias, relativa a la conservación y aprovechamiento sustentable de la vida silvestre y su hábitat en el territorio de la República Mexicana y en las zonas en donde la Nación ejerce su jurisdicción. Esta legislación engloba tanto preceptos conservacionistas como de aprovechamiento de la vida silvestre. Referente al tema de bienestar animal establece como competencia de la Federación la atención y promoción de los asuntos relativos al trato digno y respetuoso de la fauna silvestre reconociendo la facultad de colaboración entre los tres niveles de gobierno en su ámbito de jurisdicción territorial para promover y aplicar las medidas relativas al trato digno y respetuoso de la fauna silvestre.

Se define el trato digno y respetuoso en su numeral 2o fracción XLVII como las medidas que la normatividad federal -la Ley General de Vida Silvestre y su Reglamento, las normas ambientales y las normas oficiales mexicanas- e internacional -Tratados Internacionales- establecen para evitar dolor, deterioro 
físico o sufrimiento, durante su posesión o propiedad, crianza, captura, traslado, exhibición, cuarentena, comercialización, aprovechamiento, adiestramiento o sacrificio, esta fracción fue adicionada mediante reforma en el DOF el 5 de Noviembre de 2013. Así mismo se incluye el 5 de Noviembre de 2013 a través de una reforma publicada en el DOF el termino "Crueldad" definiéndolo como un acto de brutalidad, sádico o zoofílico contra cualquier animal, ya sea por acción directa, omisión o negligencia.

El bienestar animal en la Ley General de Vida Silvestre es un elemento indispensable en el aprovechamiento de la fauna silvestre ya que dentro de los límites establecidos para el uso de la fauna silvestre se encuentra la prohibición de realizar actos de crueldad conforme lo establecido en el numeral 30:

Artículo 30. El aprovechamiento de la fauna silvestre se llevará a cabo de manera que se eviten o disminuyan los daños a la fauna silvestre mencionados en el artículo anterior. Queda estrictamente prohibido todo acto de crueldad en contra de la fauna silvestre, en los términos de esta Ley y las normas que de ella deriven.

Dentro del título $\mathrm{V}$ denominado disposiciones comunes para la conservación y el aprovechamiento sustentable de la vida silvestre se consagra un apartado especializado en el trato digno y respetuoso en el capítulo VI donde se establecen los mecanismos de concurrencia de los tres órdenes de gobierno para adoptar medidas asociadas al trato digno y respetuoso para evitar o disminuir la tensión, sufrimiento, traumatismo y dolor que se pudiera ocasionar a los ejemplares de fauna silvestre durante su aprovechamiento, traslado, exhibición, cuarentena, entrenamiento, comercialización y sacrificio. Así mismo se enmarca como un requisito de los planes de trabajo de los predios e instalaciones que manejen vida silvestre en forma confinada que contengan medidas para garantizar el trato digno y respetuoso de la fauna silvestre. 
En un ámbito procedimental asociado al bienestar animal esta legislación establece que si existen faltas al trato digno y respetuoso la autoridad ambiental tiene la facultad de realizar el aseguramiento precautorio de fauna silvestre, así mismo se establece como una infracción a la Legislación ambiental el realizar actos que contravengan las disposiciones de trato digno y respetuoso a la fauna silvestre, por lo que esta legislación contiene elementos sustantivos y adjetivos asociados al bienestar de la fauna silvestre.

El bienestar animal en el sistema normativo mexicano es complejo y tiene una gama amplia de legislación que refleja un vínculo diferenciado por especie; los animales que son destinados a consumo humano se encuentran en un estatus inferior asociado a los estándares de protección que aquellas especies utilizadas como mascotas o la fauna silvestre debido a las interacciones sociales, culturales y ambientales que se construyen de la relación del humano con las demás especies.

\section{Las Normas Oficiales Mexicanas asociadas al bienestar animal.}

Las normas oficiales mexicanas son de acuerdo a lo establecido en el artículo $3^{\text {o }}$ fracción XI de la Ley Federal sobre Metrología y Normalización la regulación técnica de observancia obligatoria expedida por las dependencias competentes, establecen reglas, especificaciones, atributos, directrices, características o prescripciones aplicables a un producto, proceso, instalación, sistema, actividad, servicio o método de producción u operación, así como aquellas relativas a terminología, simbología, embalaje, marcado o etiquetado y las que se refieran a su cumplimiento o aplicación y tienen como finalidad enfocado en los animales de manera directa las siguientes:

Las características y/o especificaciones que deban reunir los productos y procesos cuando éstos puedan constituir un riesgo para la seguridad de las personas o dañar la salud humana, animal, vegetal, el medio ambiente general y laboral, o para la preservación de recursos naturales.

Las características y/o especificaciones, criterios y procedimientos que permitan proteger y promover el mejoramiento del medio ambiente y los ecosistemas, así como la preservación de los recursos naturales. 


\section{dA derecho ANIMAL la web center de los animales con derecho}

Las características y/o especificaciones, criterios y procedimientos que permitan proteger y promover la salud de las personas, animales o vegetales.

Dentro de las disposiciones emanadas del ejecutivo federal enfocado al bienestar animal una de las primeras disposiciones oficiales es la Norma Oficial Mexicana NOM-033-ZO0-1995, Sacrificio humanitario de los animales domésticos y silvestres. Esta norma se publicó en el Diario Oficial de la Federación el 16 de Julio de 1996 y tenía por objeto establecer los métodos de insensibilización y sacrificio de los animales, con el propósito de disminuir su sufrimiento, evitando al máximo la tensión y el miedo durante este evento. Delimitaba al trato humanitario como el conjunto de medidas para disminuir la tensión, sufrimiento, traumatismos y dolor a los animales durante su captura, traslado, exhibición, cuarentena, comercialización, aprovechamiento, entrenamiento y sacrificio, establecía que durante el manejo de los animales, los responsables deberán mantenerlos tranquilos, evitando los gritos, ruidos excesivos y golpes que provocasen traumatismos. Establecía que para el arreo, nunca se debería golpear a los animales con tubos, palos, varas con puntas de acero, látigos, instrumentos punzocortantes u objetos que produzcan traumatismos.

En el apartado del sacrificio humanitario se establecía por regla general el insensibilizar al animal para realizar el sacrificio de manera rápida y efectiva, en las especies que no fueran a destinarse al consumo humano solamente se podría realizar el sacrificio cuando en razón de un sufrimiento que le cause un accidente, enfermedad, incapacidad física o vejez extrema, o por la imposibilidad para su manutención, riesgo zoosanitario, por exceso en el número de los de su especie o cuando signifiquen un peligro comprobado para la salud pública.

Otra excepción para realizar el sacrificio humanitario de animales era para las escuelas de educación superior, institutos e instituciones científicas y de investigación nacionales, ya que podían realizar el sacrificio humanitario de animales para experimentación, exclusivamente con fines didácticos y de investigación para uso dentro del territorio nacional. 
Esta normatividad fue derogada por la Norma Oficial Mexicana NOM-033-SAG/ZOO2014, Métodos para dar muerte a los animales domésticos y silvestres, publicada en el DOF en 26 de Agosto del 2015, su objetivo es regular el sacrificio de animales bajo cualquier tipo de aprovechamiento garantizando buenos niveles de bienestar con el propósito de disminuir al máximo el dolor, sufrimiento, ansiedad y estrés, esta norma es más enriquecedora en el tema de bienestar animal, establece una prohibición de dar muerte a los animales por envenenamiento, drogas curariformes, paralizantes musculares, asfixia, inmersión en agua, por golpes o por cualquier otro procedimiento que les cause sufrimiento, dolor, ansiedad o que prolongue su agonía, así mismo prohíbe el acceso a los menores de edad a los lugares en donde se realice la matanza o eutanasia.

De manera indirecta al bienestar animal en el sistema normativo existen las siguientes normas oficiales mexicanas:

Norma Oficial Mexicana NOM-162-SEMARNAT-2012, Que establece las especificaciones para la protección, recuperación y manejo de las poblaciones de las tortugas marinas en su hábitat de anidación.

Norma Oficial Mexicana NOM-131-SEMARNAT-2010, Que establece lineamientos y especificaciones para el desarrollo de actividades de observación de ballenas, relativas a su protección y la conservación de su hábitat.

Norma Oficial Mexicana NOM-059-SEMARNAT-2010, Protección ambientalEspecies nativas de México de flora y fauna silvestres-Categorías de riesgo y especificaciones para su inclusión, exclusión o cambio-Lista de especies en riesgo.

Norma Oficial Mexicana NOM-135-SEMARNAT-2004, Para la regulación de la captura para investigación, transporte, exhibición, manejo y manutención de mamíferos marinos en cautiverio. 


\section{dA derecho ANIMAL la web center de los animales con derecho}

Norma Oficial Mexicana NOM-126-SEMARNAT-2000, Por la que se establecen las especificaciones para la realización de actividades de colecta científica de material biológico de especies de flora y fauna silvestres y otros recursos biológicos en el territorio nacional. Secretaría de Medio Ambiente y Recursos Naturales.

Así mismo se puede incluir en este rubro de normatividad indirecta al bienestar animal el Protocolo de atención para varamiento de mamíferos marinos, publicado en el DOF el 17 de Junio de 2014.

\section{Reforma asociada al bienestar Animal en la Ley General del Equilibrio Ecológico y Protección al Ambiente.}

La protección de los animales no humanos en el sistema jurídico mexicano se encuentra en constante evolución, el 24 de Enero de 2017 se publicó en el Diario Oficial de la Federación una reforma al artículo 87 BIS 2 de la Ley General del Equilibrio Ecológico y la Protección al Ambiente que enuncia las directrices generales para regular el trato digno y respetuoso hacia los animales en los tres órdenes de Gobierno estableciendo como principios básicos los siguientes:

I. Suministrar a los animales agua y alimento suficientes, a efecto de mantenerlos sanos y con una nutrición adecuada;

II. Proporcionar a los animales un ambiente adecuado para su descanso, movimiento y estancia, de acuerdo a cada tipo de especie;

III. Suministrar a los animales atención médica preventiva y en caso de enfermedad brindar tratamiento médico expedito avalado por un médico veterinario;

IV. Permitir a los animales la expresión de su comportamiento natural, y

V. Brindar a los animales un trato y condiciones que procuren su cuidado dependiendo de la especie.

La reforma delimita a la federación como la autoridad para expedir las normas oficiales mexicanas que determinen los principios básicos de trato digno y 
respetuoso.

Los cinco puntos enunciados en la reforma se engloban dentro del concepto teórico de bienestar animal que tiene como eje central tres elementos: el funcionamiento biológico adecuado del organismo, el estado emocional del animal y las posibilidades de expresar un comportamiento normal propias de cada especie. ${ }^{8}$ Así mismo tiene una correlación con las cinco libertades básicas de los animales que adoptó el Farm Animal Welfare Council en 19799. De acuerdo con el denominado principio de las cinco libertades, el bienestar de un animal queda garantizado cuando se cumplen los cinco requisitos siguientes:

El animal no sufre sed, hambre ni malnutrición, porque tiene acceso a agua de bebida y se le suministra una dieta adecuada a sus necesidades.

El animal no sufre estrés físico ni térmico, porque se le proporciona un ambiente adecuado, incluyendo refugio frente a las inclemencias climáticas y un área de descanso cómoda.

El animal no sufre dolor, lesiones ni enfermedades, gracias a una prevención adecuada y/o a un diagnóstico y tratamiento rápidos.

El animal es capaz de mostrar la mayoría de sus patrones normales de conducta, porque se le proporciona el espacio necesario y las instalaciones adecuadas, y se aloja en compañía de otros individuos de su especie.

El animal no experimenta miedo ni distrés, porque se garantizan las condiciones necesarias para evitar el sufrimiento mental. ${ }^{10}$

\footnotetext{
${ }^{8}$ Fraser, D., Weary, D., Pajor, E., \& Milligan, B. A scientific conception of animal welfare that reflects ethical concerns. pp. 187-205. Animal welfare, 6, (1997); Duncan, I., Fraser, D. Understanding animal welfare. Animal Welfare. Animal Welfare. (1997); Von Keyserlingk, M., Rushen, J., de Passillé, A., \& Weary, D. Invited review: The welfare of dairy cattle-Key concepts and the role of science. Journal of Dairy Science, 92(9), (2009).

${ }^{9}$ Farm Animal Welfare Council. Farm Animal Welfare in Great Britain: Past, Present and Future. http://www.fao.org/fileadmin/user upload/animalwelfare/ppf-report091012.pdf (Octubre, 2009).

${ }^{10}$ Manteca, X., Mainau, E. y Temple, D. ¿Qué es el bienestar animal?. Ficha técnica sobre bienestar de animales de granja. (2012). disponible en https://www.fawec.org/media/com lazypdf/pdf/fs1es.pdf
} 
Los cinco requisitos para propiciar las cinco libertades tienen una correlación con el texto de la reforma, empero, el principio básico III no vincula que las actividades de atención médica preventiva o el tratamiento médico por enfermedad se realice con el fin de que el animal no sufra dolor, lesiones ni enfermedades, esto tiene una gran importancia ya que las actividades zootécnicas pueden trasgredir el bienestar animal, ya que es diferenciado un trato veterinario con un enfoque a la actividad económica que al bienestar animal. Sin embargo, en esencia, las cinco libertades se ven reflejadas en el texto de la reforma.

Esta reforma marca las directrices en materia de bienestar animal asociado a todos los animales sin excluir por especie, es decir, estos ejes deben de ser los estándares mínimos que el humano debe de brindar a los demás animales.

Esta reforma incluye una prohibición de organizar, inducir o provocar peleas de perros y establece que los tres órdenes de gobierno deben de incorporar esta prohibición en su competencia y determinar las sanciones correspondientes.

Actualmente en México existen 31 entidades federativas que tienen una legislación administrativa asociada a los animales y su bienestar, solamente el estado de Oaxaca no tiene legislación en materia de bienestar animal, en 28 estados en sus legislaciones locales se prohíbe realizar actos que implique azuzar o realizar peleas de animales, en el estado de Yucatán su legislación no establece ninguna prohibición ni directa o indirecta y en los estados de Nayarit y Jalisco se establece la prohibición de manera indirecta por ser laxa y con una redacción que no permite certeza jurídica. En materia penal el Código Penal Federal tipifica en su numeral 420 fracción $V$ a nivel Federal el daño a ejemplares de vida silvestre, y en un ámbito local en 25 Estados de México se encuentra tipificado como delito el maltrato animal. ${ }^{11}$

\footnotetext{
${ }^{11}$ Morales, A. (2016). Tipificación del maltrato animal en el Estado de Hidalgo, México. Derecho Animal DA. Universitat Autònoma de Barcelona.
} 
Esta reforma es uno de los cimientos para que se establezcan disposiciones adecuadas para la prohibición de las peleas de perros y establecer las sanciones correspondientes en los tres órdenes de gobierno, siendo importante analizar que el 8 de Diciembre de 2016 la Cámara de Diputados aprobó un dictamen de Reforma al Código Penal Federal para la tipificación como delito del orden Federal actividades relacionadas con peleas de perros que al englobarse en un orden penal Federal se rebasa la esfera individualizada de los delitos contra los animales en el fuero Común y pasan a ser parte integral del bienestar de los mexicanos y los intereses de la Federación.

Las iniciativas asociadas a la tipificación de las peleas de perros se presentó de una forma dual, por una parte Diputados integrantes del Partido Verde Ecologista de México $^{12}$ y la segunda iniciativa fue propuesta por los Diputados Clemente Castañeda Hoeflich y Verónica Delgadillo García del Partido Movimiento Ciudadano y con el Diputado Elías Octavio Íñiguez de Partido Acción Nacional. ${ }^{13}$ El 8 de Diciembre de 2016 La Cámara de Diputados aprobó el dictamen de estas dos iniciativas por lo que conforme a la Ley Orgánica del Congreso General de los estados Unidos Mexicanos, la Cámara de Senadores es el organismo que turna a sus comisiones de Justicia y Estudios legislativos para realizar la revisión correspondiente, la iniciativa presentada quedo formulada de la siguiente manera:

Artículo 419 Bis.- Se impondrá pena de seis meses a cinco años de prisión y el equivalente de doscientos a dos mil días multa a quien:

I. Críe o entrene a un perro con el propósito de hacerlo participar en cualquier exhibición, espectáculo o actividad que involucre una pelea entre dos o más perros para fines recreativos, de entretenimiento o de cualquier otra índole; II. Posea, transporte, compre o venda perros con el fin de involucrarlos en cualquier exhibición, espectáculo o actividad que implique una pelea entre dos o más perros;

\footnotetext{
12 Publicada en la Gaceta Parlamentaria, año XX, número 4666-V, jueves 24 de noviembre de 2016.

13 Publicada en la Gaceta Parlamentaria, año XX, número 4669-VI, martes 29 de noviembre de 2016.
} 
III. Organice, promueva, anuncie, patrocine o venda entradas para asistir a espectáculos que impliquen peleas de perros;

IV. Posea o administre una propiedad en la que se realicen peleas de perros con conocimiento de dicha actividad;

V. Ocasione que menores de edad asistan o presencien cualquier exhibición, espectáculo o actividad que involucre una pelea entre dos o más perros, o

VI. Realice con o sin fines de lucro cualquier acto con el objetivo de involucrar a perros en cualquier exhibición, espectáculo o actividad que implique una pelea entre dos o más perros.

La sanción a que se hace mención en el párrafo anterior, se incrementará en una mitad cuando se trate de servidores públicos.

Incurre en responsabilidad penal, así mismo, quien asista como espectador a cualquier exhibición, espectáculo o actividad que involucre una pelea entre dos o más perros, a sabiendas de esta circunstancia. En dichos casos se impondrá un tercio de la pena prevista en este articulo. ${ }^{14}$

\section{Conclusiones.}

El dinamismo jurídico asociado a los derechos de los animales y su bienestar se encuentra en constante evolución. México actualmente cuenta con normatividad asociada al bienestar animal en la mayoría de las legislaciones estatales enfocándose primordialmente en animales domésticos y aquellos que no se consideren plaga, a nivel federal existen normas de bienestar animal diferenciadas por especie animales silvestres en vida libre y bajo confinamiento y animales domésticos-, sin embargo, la reforma al artículo 87 Bis 2 de la LGEEPA establecen una regulación sobre trato digno y respetuoso en sentido lato a cualquier especie animal, rompiendo la visión especista de la legislación. Esta reforma establece una

\footnotetext{
${ }_{14}$ Minuta Proyecto de Decreto por el que se adiciona el artículo 419 Bis al Código Penal Federal, con número

CD-LXIII-II-1P-D124. aprobado en esta fecha por la Cámara de Diputados del Honorable Congreso de la Unión. Ciudad de México, a 8 de diciembre de 2016.

http://www.senado.gob.mx/sgsp/gaceta/63/2/2016-12-13-

1 /assets/documentos/Minuta art 419bis CPF.pdf
} 


\section{dA derecho ANIMAL la web center de los animales con derecho}

obligación a los entes gubernamentales de los tres órdenes de gobierno para regular el trato digno y respetuoso para todos los animales y se establece la obligación de crear las normas oficiales mexicanas que determinen los principios básicos de trato digno y respetuoso. Actualmente la normatividad enfocada en el bienestar animal es laxa por lo que es necesario contar con mayor normatividad tanto sustantiva como adjetiva para que no sean una disposición en blanco. La reforma a la LGEEPA en bienestar animal es de gran importancia para la reestructuración del derecho animal en México ya que actualmente la legislación y las políticas públicas no han tenido la incidencia suficiente para dar una protección idónea a la fauna en México.

\section{Normatividad consultada.}

Organización Mundial de Sanidad Animal. [OIE]. 84a. Sesión General de la Asamblea Mundial de Delegados de la OIE: Código Sanitario para los Animales Terrestres. (Mayo, 2016).

Ley General del Equilibrio Ecológico y la Protección al Ambiente. Publicada en el Diario Oficial de la Federación el 28 de enero de 1988. (México).

Ley General de Vida Silvestre. Publicada en el Diario Oficial de la Federación el 3 de Julio de 2000. (México).

Ley de Sanidad Fitopecuaria de los Estados Unidos Mexicanos. Publicada en el Diario Oficial de la Federación el 9 de septiembre de 1940. (México).

Ley de Sanidad Fitopecuaria de los Estados Unidos Mexicanos. Publicada en el Diario Oficial de la Federación el 13 de Diciembre de 1974. (México).

Ley Federal de Sanidad Animal. Publicada en el Diario Oficial de la Federación el 18 de Junio de 1993. (México).

Ley Federal de Sanidad Animal. Publicada en el Diario Oficial de la Federación el 25 de Julio de 2007. (México).

Ley Federal sobre Metrología y Normalización. Publicada en el Diario Oficial de la Federación el 1 de julio de 1992. (México). 
Norma Oficial Mexicana NOM-033-ZOO-1995, Sacrificio humanitario de los animales domésticos y silvestres. [Secretaría de Agricultura, Ganadería y Desarrollo Rural]. Publicada en el Diario Oficial de la Federación el 16 de julio de 1996.

Norma Oficial Mexicana NOM-033-SAG/Z00-2014, Métodos para dar muerte a los animales domésticos y silvestres. [Secretaría de Agricultura, Ganadería, Desarrollo Rural, Pesca y Alimentación]. Publicada en el Diario Oficial de la Federación el 26 de Agosto del 2015.

Norma Oficial Mexicana NOM-162-SEMARNAT-2012, Que establece las especificaciones para la protección, recuperación y manejo de las poblaciones de las tortugas marinas en su hábitat de anidación. [Secretaría de Medio Ambiente y Recursos Naturales]. Publicada en el Diario Oficial de la Federación el 1 de Febrero de 2013.

Norma Oficial Mexicana NOM-131-SEMARNAT-2010, Que establece lineamientos y especificaciones para el desarrollo de actividades de observación de ballenas, relativas a su protección y la conservación de su hábitat. [Secretaría de Medio Ambiente y Recursos Naturales]. Publicada en el Diario Oficial de la Federación el 17 de Octubre de 2011.

Norma Oficial Mexicana NOM-059-SEMARNAT-2010, Protección ambientalEspecies nativas de México de flora y fauna silvestres-Categorías de riesgo y especificaciones para su inclusión, exclusión o cambio-Lista de especies en riesgo. [Secretaría de Medio Ambiente y Recursos Naturales]. Publicada en el Diario Oficial de la Federación el 30 de Diciembre de 2010.

Norma Oficial Mexicana NOM-135-SEMARNAT-2004, Para la regulación de la captura para investigación, transporte, exhibición, manejo y manutención de mamíferos marinos en cautiverio. [Secretaría de Medio Ambiente y Recursos Naturales]. Publicada en el Diario Oficial de la Federación el 27 de Agosto de 2004. Norma Oficial Mexicana NOM-126-SEMARNAT-2000, Por la que se establecen las especificaciones para la realización de actividades de colecta científica de material biológico de especies de flora y fauna silvestres y otros recursos biológicos en el territorio nacional. Secretaría de Medio Ambiente y Recursos Naturales. [Secretaría 


\section{dA derecho ANIMAL la web center de los animales con derecho}

de Medio Ambiente y Recursos Naturales]. Publicada en el Diario Oficial de la Federación el 20 de Marzo de 2001.

Protocolo de atención para varamiento de mamíferos marinos. [Secretaría de Medio Ambiente y Recursos Naturales]. Publicada en el Diario Oficial de la Federación el 17 de Junio de 2014. 